\title{
Effect of a high carbohydrate diet on core temperature during prolonged exercise
}

\author{
M.P. Schwellnus MBBCh, MSc ${ }^{1}$, N.F. Gordon MBBCh, $\mathrm{PhD}^{2}$, G.G. van Zyl BA (Hons) ${ }^{3}$, \\ J.F. Cilliers, PhD ${ }^{3}$, H.C. Grobler, BA (Hons) ${ }^{3}$, J. Kuyl MBChB, FFPath ${ }^{4}$ and H.W. Kohl \\ MSPH $^{2}$ \\ ${ }^{1}$ MRC/UCT Bioenergetics of Exercise Research Unit, University of Cape Town Medical School, Cape Town, \\ South Africa \\ 2 Institute for Aerobics Research, Dallas, Texas; Department of Chemical Pathology, University of the \\ Witwatersrand, Johannesburg, South Africa \\ ${ }^{3}$ Biokinetic Centre, 1 Military Hospital, Pretoria, South Africa \\ 4 South African Insitute for Medical Research, Johannesburg, South Africa
}

This study compared the effects of a highcarbohydrate and a mixed diet on core temperature responses to prolonged exercise in six male competitive cyclists (age $=22.2 \pm 1.9$ years). This study, the first to investigate the effect of a high-carbohydrate diet on exercise core temperature in humans, therefore suggests that three days of increased dietary carbohydrate intakes do not evoke any deleterious thermoregulatory responses during prolonged submaximal exercise.

Keywords: Exercise, diet, carbohydrates, temperature

\section{Introduction}

The practice of consuming a high-carbohydrate diet in the days preceding competitive endurance events is common amongst athletes ${ }^{1,2}$. The resultant increase in muscle glycogen stores has been shown to delay the onset of fatigue and increase the ability to perform prolonged exercise ${ }^{1,3,4}$. However, competitive endurance events are associated with an accentuated risk of heat injury, particularly when conducted in hot and humid environments ${ }^{5}$, and the effect of a high-carbohydrate diet on exercise thermoregulation has yet to be studied in humans. This is of concern because animal studies suggest that although glucose infusion during exercise may reduce thermal stress $^{6,7}$, a high-carbohydrate diet might in fact exaggerate the core temperature response ${ }^{8}$. Accordingly, we investigated the effect of a highcarbohydrate diet on the thermoregulatory responses of six competitive cyclists during 150 minutes of submaximal exercise.

Address for correspondence: Dr Martin P. Schwellnus, MRC/UCT

Bioenergetics of Exercise Research Unit, Department of

Physiology, University of Cape Town Medical School,

Observatory, 7925, South Africa

(C) 1990 Butterworth-Heinemann Ltd

0306-4179/90/020099-04

\section{Materials and methods}

Subjects

Six healthy male competitive endurance cyclists served as subjects. All were volunteers and gave written, informed consent. Physical characteristics of the subjects are documented in Table 1.

\section{Maximal oxygen uptake}

Each subject's maximal oxygen uptake was determined prior to the thermoregulatory investigations. Maximal graded exercise testing was performed using a calibrated Monark cycle ergometer. The starting workload $(80 \mathrm{~W})$ was increased by $40 \mathrm{~W}$ every three minutes until volitional exhaustion. The pedal frequency was maintained at 80 r.p.m. throughout each test. During exercise, subjects breathed through a low-resistance Hans Rudolph valve and the relevant respiratory variables were determined over each minute using automated open circuit spirometry (Gould 9000 IV Computerized Pulmonary Lab). the system's dry rolling seal spirometer, paramagnetic oxygen analyser and infra-red absorption carbon dioxide analyser were calibrated immediately before each test using standard procedures. The peak oxygen uptake attained during graded exercise testing was taken as the maximal oxygen uptake.

\section{Dietary intervention}

Each subject performed two 150 minute submaximal exercise tests on a calibrated Monark cycle ergometer, at least 10 days apart. Four days before each test,

Table 1. Physical characteristics of subjects

\begin{tabular}{lc}
\hline Age $(\mathrm{yr})$ & $22.2 \pm 1.9$ \\
Weight $(\mathrm{kg})$ & $72.46 \pm 4.75$ \\
Height $(\mathrm{cm})$ & $178 \pm 6$ \\
$\mathrm{VO}_{2} \max (\mathrm{ml} / \mathrm{kg} / \mathrm{min})$ & $64.0 \pm 5.8$
\end{tabular}

Values are mean $\pm S D ; n=6 ; \mathrm{VO}_{2} \max =$ maximal oxygen uptake 
subjects completed a compulsory intense training session of at least 2 hours duration, in order to deplete their muscle glycogen stores 9 . During the three days prior to both submaximal exercise tests subjects adhered to a specific diet, prescribed in a randomized crossover fashion. The prescribed diets were either a high-carbohydrate or a mixed diet, containing $>500 \mathrm{~g}$ carbohydrate/day or $<200 \mathrm{~g}$ carbohydrate/day, respectively ${ }^{9}$. No strenuous physical activity was performed during the dietary intervention period.

\section{Thermoregulatory investigation}

Subjects reported to the laboratory at the same time of day on each of the two experimental days. Meals and fluids, with the exception of water, were provided for 2 hours before exercise. Water was consumed ad libitum until \pm 15 minutes before exercise, at which time all subjects were required to drink $200 \mathrm{ml}$ of tap water. Subjects were acclimated for 60 minutes before exercise in the environmentally controlled laboratory, where the dry bulb temperature $\left( \pm 21^{\circ} \mathrm{C}\right)$ and relative humidity ( \pm 55 per cent) remained constant for both tests.

Each submaximal test consisted of 150 minutes cycling, interrupted for five minutes after 60 and 120 minutes in order to facilitate nude body-weight and rectal temperature measurement. The pedal frequency was maintained at 80 r.p.m. during cycling and workloads were chosen to elicit \pm 50 per cent of the predetermined maximal oxygen uptake. Individual workloads were identical for both 150 minutes exercise bouts. During exercise, only cycling shorts were worn, and $200 \mathrm{ml}$ of tap water was consumed every 20 minutes.

Heart rates, rectal temperature, oesophageal temperatures and nude body-weights were measured immediately before exercise and at 60, 120, and 150 minutes of exercise. During exercise tests, heart rates and oesophageal temperatures were recorded while the subjects were cycling, whereas rectal temperatures and nude body-weights were recorded after three minutes of standing rest. Heart rates were determined by counting the radial pulse for 30 seconds. Rectal temperature was measured $\pm 10 \mathrm{~cm}$ beyond the external anal sphincter. Oesophageal temperature was measured at heart level using the electrocardiographic method ${ }^{10}$. Copper-constantan thermocouples were used for all temperature measurements. On completion of the study thermocouples were calibrated in a stirred water bath against a certified thermometer. Nude body-weights were recorded using a balance scale sensitive to a change of $50 \mathrm{~g}$. Sweat rates were calculated from weight differences, taking water ingested and urine voided into account.

Venous blood samples were taken from an antecubital vein immediately before exercise and, while the subjects were cycling, at 60 and 150 minutes of exercise. Percentage changes in plasma volume were calculated from haemoglobin and haematocrit values using the formula of Dill and Costill ${ }^{11}$. Ventilatory responses were measured over a five minute period, after 55 and 145 minutes of exercise,
Table 2. Effect of a high-carbohydrate $(C)$ and mixed $(M)$ diet on cardiorespiratory responses during 150 minutes of cycling

\begin{tabular}{|c|c|c|c|c|}
\hline & Rest & $60 \min$ & $120 \min$ & $150 \min$ \\
\hline \multicolumn{5}{|c|}{ HR (beats/min) } \\
\hline $\begin{array}{l}\text { Cdiet } \\
M \text { diet }\end{array}$ & $\begin{array}{l}58 \pm 13 \\
59 \pm 13\end{array}$ & $\begin{array}{l}127 \pm 14 \\
129 \pm 13\end{array}$ & $\begin{array}{l}137 \pm 12 \\
135 \pm 15\end{array}$ & $\begin{array}{l}141 \pm 14 \\
139 \pm 18\end{array}$ \\
\hline \multicolumn{5}{|l|}{ VE (I/min) } \\
\hline C diet & - & $67.2 \pm 16$ & - & $68.3 \pm 13.3$ \\
\hline M diet & & $62.0 \pm 13.2$ & & $65.2 \pm 13.5$ \\
\hline \multicolumn{5}{|c|}{$\mathrm{VO}_{2}(1 / \min )$} \\
\hline $\begin{array}{l}\text { C diet } \\
\text { M diet }\end{array}$ & - & $2.35 \pm 0.23$ & - & $2.46 \pm 0.27$ \\
\hline Molet & & $2.13 \pm 0.28$ & & $2.32 \pm 0.33$ \\
\hline \multicolumn{5}{|c|}{$\% \mathrm{VO}_{2} \max$} \\
\hline C diet & - & $52 \pm 4.0$ & - & $54 \pm 4$ \\
\hline M diet & - & $50 \pm 2.6$ & - & $55 \pm 6.0$ \\
\hline \multicolumn{5}{|l|}{ RER } \\
\hline C diet & - & $1.01 \pm 0.04^{*}$ & - & $0.97 \pm 0.05^{*}$ \\
\hline M diet & - & $0.97 \pm 0.07$ & - & $0.93 \pm 0.03$ \\
\hline \multicolumn{5}{|l|}{ RPE } \\
\hline C diet & - & $12.5 \pm 1.2$ & $12.7 \pm 0.8$ & $12.5 \pm 1.8$ \\
\hline M diet & - & $12.3 \pm 0.8$ & $12.7 \pm 1.0$ & $13.0 \pm 1.1$ \\
\hline
\end{tabular}

Values are mean $\pm S D ; n=6 ; H R=$ heart rate; RPE - rate of perceived exertion; $R E R=$ respiratory exchange ratio; $V E=$ pulmonary ventilation; $\mathrm{VO}_{2}=$ oxygen uptake; $\% \mathrm{VO}_{2} \max =$ percentage of maximal oxygen uptake.

* $C$ and $M$ diets differed significantly where indicated $(P<0.05)$.

as earlier outlined. Each participant's subjective perception of effort was evaluated, using the Borg $6-20$ perceived exertion scale ${ }^{12}$, at 60,120 and 150 minutes of exercise.

\section{Statistics}

Standard analysis of variance techniques were used to assess differences between treatments and among time periods. Polynomial contrasts were used to assess the response pattern in analyses with more than two time periods. Statistical significance was established at the 0.05 probability level.

\section{Results}

As expected, nude body-weights were significantly higher $(P<0.05)$ with the high-carbohydrate diet $(72.46 \pm 4.75 \mathrm{~kg})$ than with the mixed diet $(71.41 \pm$ $5.06 \mathrm{~kg}$ ). This increase in weight most likely reflects an increase in glycogen and water storage with the high-carbohydrate $\operatorname{diet}^{13}$.

The effect of dietary intervention on cardiorespiratory responses to exercise is documented in Table 2. Oxygen uptakes, whether expressed on an absolute or relative basis, were not significantly altered by the ingestion of a high-carbohydrate diet. In contrast, respiratory exchange ratios were signifcantly higher $(P<0.05)$ with the high-carbohydrate diet than with the mixed diet. The very high values obtained in this study (0.93-1.01) are probably related to the carbohydrate meal taken two hours before the exercise bout. Other possibilities are hyperventilation and poorly calibrated equipment. The latter is unlikely as 


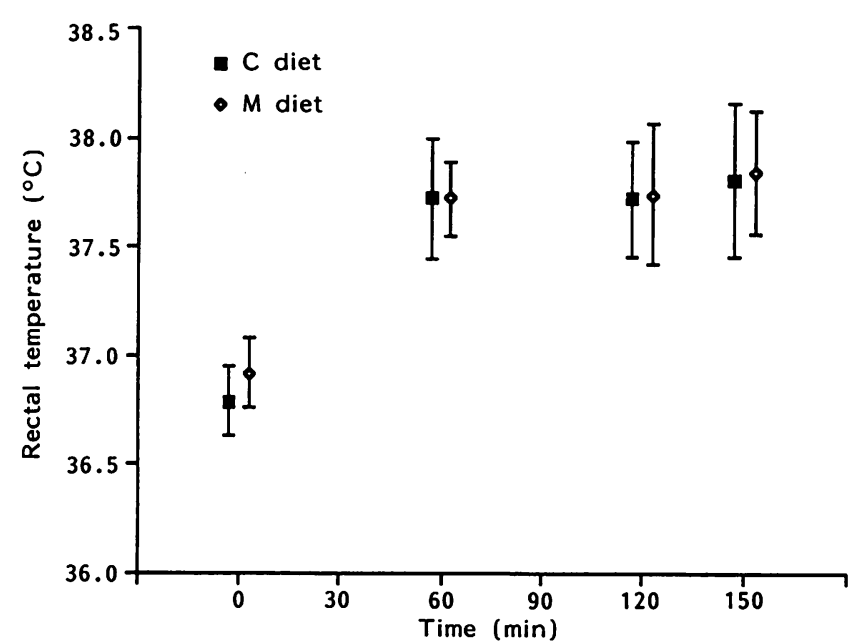

Figure 1. Effect of a high-carbohydrate (C) and mixed (M) diet on the rectal temperature response to $150 \mathrm{~min}$ of cycling. Values are means $\pm S D ; N=6$. Rectal temperature responses (both absolute values and changes with time) did not differ significantly for the two diets

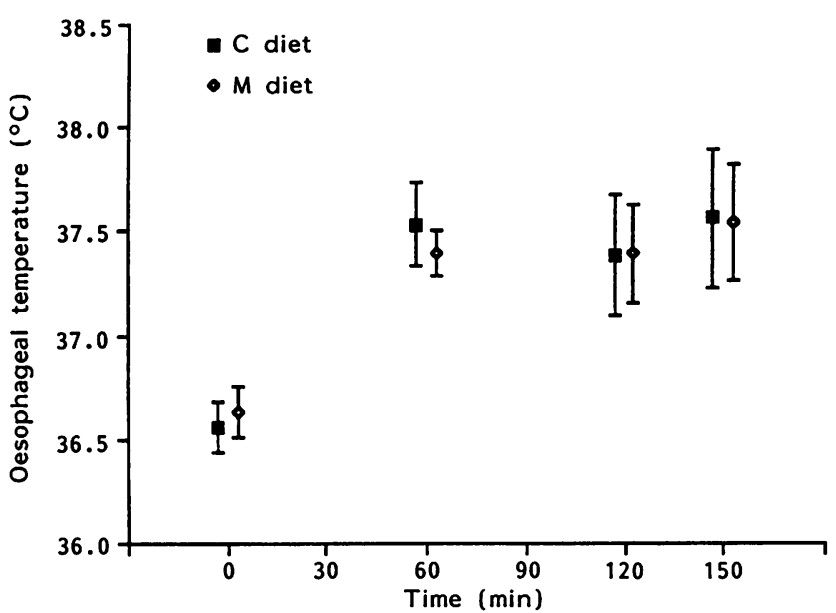

Figure 2. Effect of a high-carbohydrate (C) and mixed (M) diet on the oesophageal temperature response to $150 \mathrm{~min}$ of cycling. Values are means $\pm \mathrm{SD} ; n=6$. Oesophageal temperature responses (both absolute values and changes with time) did not differ significantly for the two diets

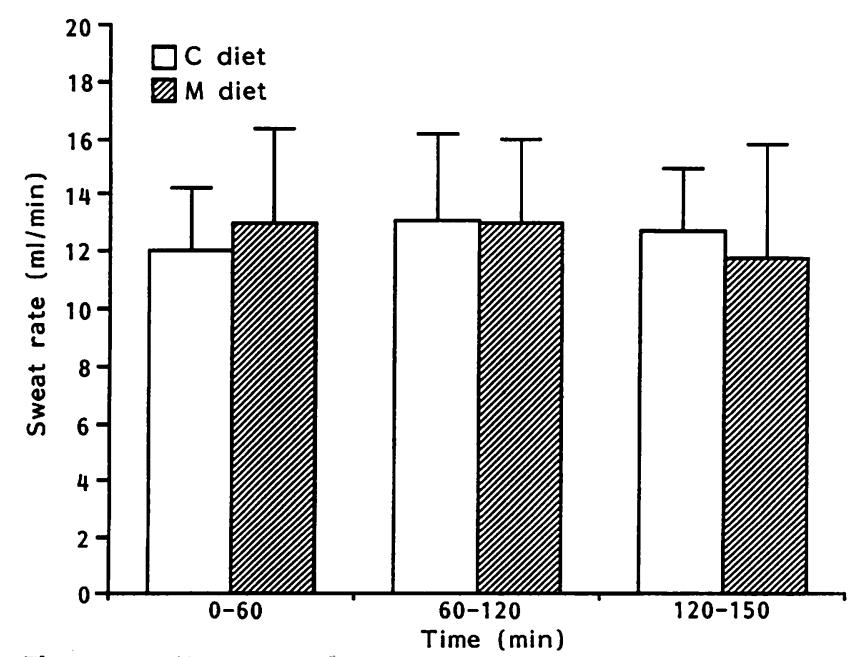

Figure 3. Effect of a high-carbohydrate (C) and mixed (M) diet on the sweat rate during $150 \mathrm{~min}$ of cycling. Values are means $\pm S D ; n=6$. Sweat rates did not differ significantly with the two diets the equipment was calibrated before and after each test. The difference in RER that was observed is indicative of an increased reliance on carbohydrate metabolism for energy production during exercise with the high carbohydrate diet ${ }^{14}$.

Rectal (Figure 1) and oesophageal (Figure 2) temperature responses to exercise were essentially equivalent with the two diets. Similarly, sweat rates (Figure 3) and percentage changes in plasma volume (Table 3) were similar with the high-carbohydrate and mixed diets.

\section{Discussion}

A direct relationship between dietary carbohydrate content and the relative contribution of different metabolic substrates to energy production during exercise is well established ${ }^{1,15}$. Recent studies have further indicated that changes in fuel utilization during exercise may modify thermoregulatory responses. More specifically, glucose infusion during prolonged exercise has been shown to attenuate core temperature rises in several animal studies ${ }^{6,7}$. In contrast, exaggerated core temperature responses to exercise have been observed in animals as a result in insulin-induced hypoglycaemia or inhibition of glucose utilization by 2-deoxy-D-glucose administration $^{16}$. Although these animal studies suggest that an enhanced contribution of carbohydrates to muscle metabolism may reduce exercise hypothermia, Owen et al. ${ }^{17}$ were unable to demonstrate a significant effect of carbohydrate ingestion during exercise on thermoregulation in humans. Moreover, Francesconi and Hubbard $^{8}$ have documented findings that are in fact contrary to the hypothesis that the rise in core temperature during exercise can be attenuated by an increased contribution of carbohydrates to muscle metabolism. In their study, rats placed on a high-carbohydrate diet for four days prior to exercise in heat displayed higher resting and exercise core temperatures than those on a normal diet.

When extrapolated to humans, the results of the study conducted by Francesconi and Hubbard ${ }^{8}$ imply that the practice of consuming a diet high in carbohydrates during the days preceding competitive endurance events may actually accentuate the risk for hyperthermia. However, in our study, the first to investigate the effect of a high-carbohydrate diet on exercise thermoregulation in humans, three days of increased dietary carbohydrate intake failed to

Table 3. Effect of a high-carbohydrate and mixed diet on the percentage change in plasma volume during 150 minutes of cycling

\begin{tabular}{lll}
\hline & \multicolumn{2}{l}{ \% Change in Plasma Volume } \\
\cline { 2 - 3 } & $0-60 \mathrm{~min}$ & $60-150 \mathrm{~min}$ \\
\hline $\begin{array}{ll}\text { High-carbohydrate diet } \\
\text { Mixed diet }\end{array}$ & $-2.6 \pm 6.1$ & $-0.6 \pm 2.7$ \\
\hline
\end{tabular}

Values are mean $\pm S D ; n=6$

Values did not differ significantly 
significantly alter rectal and oesophageal temperatures, sweating, or plasma volume changes during 150 minutes of submaximal cycling performed in a cool environment. On the basis of our data, it therefore appears that an increased contribution of carbohydrates to muscle metabolism as a result of a high-carbohydrate diet does not evoke any deleterious thermoregulatory consequences during prolonged exercise in humans. However, additional research involving more intense exercise and less favourable environmental conditions will be needed to fully clarify the situation.

\section{References}

1 Costill, D.L. Carbohydrates for exercise: dietary demands for optimal performance Int J Sports Med 1989, 9, 1-18

2 Sherman, W.M. Carbohydrate, muscle glycogen, and improved performance Phys Sports Med 1987, 15, 157-164

3 Ahlborg, B., Bergstrom, J., Ekelund, L. and Hultman, E. Muscle glycogen and muscle electrolytes during prolonged physical exercise Acta Physiol Scand 1967, 70, 129-142

4 Hermansen, L., Hultman, E. and Saltin, B. Muscle glycogen during prolonged severe exercise Acta Physiol Scand 1967, 71, 129-139

5 Fortney, S.M. and Vroman, N.B. Exercise, performance and temperature control: temperature regulationd uring exercise and implications for sports performance and training Sports Med 1985, 2, 8-20

6 Francesconi, R.P. and Mager, M. Hypothermia induced by 5-thio-D-glucose: effects on treadmill performance in the heat Aviat Space Environ Med 1980, 51, 754-758
7 Kruk, B., Nazar, K., Kaciuba-Uscilko, H. and Kozlowski, S. Enhanced glucose availability for working muscles reduces exercise hyperthermia in dogs Eur $J$ Appl Physiol 1987, 56, 577-582

8 Francesconi, R.P. and Hubbard, R.W. Dietary manipulation and exercise in the heat: thermoregulatory and metabolic effects in rats Aviat Space Environ Med 1986, 57, 31-35

9 Noakes, T.D. Lore of Running. Oxford University Press, Cape Town, 1985

10 Brengelmann, G.L., Johnson, J.M. and Hong, P.A. Electrocardiographic verification of esophageal temeprature probe position J Appl Physiol: Respirat Environ Exercise Physiol 1979, 47, 638-642

11 Dill, D.B. and Costill, D.L. Calculation ofpercentage changes in volumes of blood, plasma and red cells in dehydration J Appl Physiol 1974, 37, 247-248

12 Borg, G.A. Perceived exertion: a note on "history" and methods Med Sci Sports 1973, 5, 90-93

13 Olsson, K-E. and Saltin, B. Variation in total body water with muscle glycogen changes in man Acta Physiol Scand 1970, 80, 11-18

14 Jansson, E. On the significance of the respiratory exchange ratio after different diets during exercise in man Acta Physiol Scand 1982, 114, 103-110

15 Gollnick, P.D. Energy metabolism and prolonged exercise. In: Lamb, D.R. and Murray, R. (eds). Perspective in exercise science andsports medicine. Volume I: Prolonged exercise. Benchmark Press, Inc., Indianaplis, 1988

16 Turlejska, E. and Nazar, K. The effect of insulin or 2-deoxy-D-glucose administration on body temperature during physical exercise in dogs Bull Acad Pol Sci 1977, 24, 687-690

17 Own, M.D., Kregel, K.C., Wall, P.T. and Gisolfi, C.V. Effects of ingesting carbohydrate beverages during exercise in the heat Med Sci Sports Exerc 1986, 18, 568-575 